\title{
Reflexiones sobre pobreza, riqueza y vivienda, desde algunos pensadores griegos, santo Tomás de Aquino y los clásicos
}

\author{
Olga Marina García Norato* \\ Fray Juan Ubaldo López Salamanca O. P.** \\ Ana Hamón Naranjo*** \\ María IsABel Novo-CORTI $* * *$
}

\section{Introducción}

T os problemas económicos de la pobreza y la acumulación desigual Lde la riqueza, se han evidenciado a través de la historia como limitantes del desarrollo humano. Este escrito hace referencia a esos dos problemas y a la vivienda -concebida a su vez como fuente de acumulación de riqueza en la economía y también referente de bienestar o desigualdad-, desde autores de la antigüedad que dieron lugar a desarrollos teóricos modernos, haciendo ver la pertinencia de esos aportes en nuestros días.

* Economista, Ph. D. en Historia, magíster en Desarrollo Rural, especialista en Finanzas. Docente Maestría en Ciencias Económicas, líder del grupo de investigación Economía y Humanismo, Universidad Santo Tomás, Bogotá, Colombia.

** Magíster en Pedagogía, contador público, licenciado en Filosofía, bachiller en Teología, Rector General Universidad Santo Tomás, Colombia. Grupo de investigación Economía y Humanismo, Universidad Santo Tomás, Bogotá, Colombia.

***Administradora de empresas, Ph. D. en Educación, magíster en Desarrollo Rural, especialista en Mercados y Finanzas. Grupo de investigación Hisula, Universidad Pedagógica y Tecnológica de Colombia, Tunja, Colombia.

****Ph. D. en Economía, Universidad de la Coruña, España. 


\section{La noción de pobreza desde autores griegos, santo Tomás y los clásicos}

Los griegos reflexionaron sobre el tema de la pobreza desde la democracia. Jenofonte ${ }^{1}$ afirmó que la democracia concede mejores oportunidades a los pobres y que, al alcanzar este sistema político su máxima expresión, los pobres se encuentran bien (Nieto, 2010). Aristóteles definió a los pobres como aquellos que carecen de lo necesario. Consideró que la pobreza extrema es mala en sí misma y origen de otros males, razón por la cual debía ser atendida por sociedades regidas por principios de justicia. En opinión de Aristóteles², el término "pobre” alude a los solidarios de la democracia: “... debe decirse que la democracia existe cuando son los libres los que detentan la soberanía [...] la democracia existe cuando una mayoría de ciudadanos libres, incluidos los pobres, ejercen la soberanía..." (Aristóteles, La Retórica, 1372, p. 20). Y, en otra perspectiva, expresa la idea de que el bienestar de la población obedece a la fecundidad de la tierra y al trabajo humano.

Santo Tomás, al referirse a la libertad y la perfección cristiana como finalidades últimas del ser humano, no defiende la pobreza ni enaltece la riqueza, simplemente las considera como instrumentos para alcanzar la perfección cristiana. "La pobreza es un bien en la medida en que libere a los hombres de los vicios asociados a la riqueza, pero en la medida en que impide el bien que la riqueza puede traer consigo, en particular el sustento de sí y el de otros, la pobreza es un mal” (Lanas, 2007, p. 13).

Adam Smith afirmó que la inequidad genera pobreza, contrario a la acumulación de capital que genera riqueza. A partir del principio económico de especialización y división del trabajo, Smith señaló que las sociedades generan excedentes, pero solo unos se los apropian mientras otros padecen las consecuencias de la distribución desigual.

1 Constitución de los Atenienses I. 1. Citado por Guntiñas, 1984.

2 Atenienses. La Política. 
Márquez y Silva (2008), destacan de Smith la afirmación de que “... el trabajo es tratado como una mercancía más, es decir, que tiene un precio real y un precio nominal; el precio real representa para una mercancía la cantidad de cosas necesarias y convenientes de la vida que se entregan a cambio de esta, y el precio nominal es la cantidad de dinero que es ofrecida por esa mercancía. De esta forma el trabajador es rico o pobre de acuerdo al valor real de la mercancía que produzca".

Posteriormente en el libre mercado, se forjaron grandes brechas e inequidad en la distribución de la riqueza, a pesar de establecerse que el equilibrio del empleo y los precios se generaban a partir de la oferta, así, llegó el momento en la historia económica en el que no funcionó la teoría de los clásicos y se concibió la crisis de 1929, donde no hubo respuesta ni para el equilibrio de precios ni para el pleno empleo a partir de la oferta agregada; es entonces cuando surge Keynes como el salvador de la economía mundial, con su teoría general del empleo, el interés y el dinero, quien establece otro aporte importante a la economía, con la intervención del Estado para regular precios y pleno empleo, a partir de la demanda agregada. La teoría keynesiana orientó la intervención del Estado mediante políticas públicas fiscales, monetarias y cambiarias, en aras de apoyar el crecimiento económico.

El crecimiento económico que se evidencia en las economías del mundo, en el resultado de indicadores como el producto interno bruto (PIB) y el ingreso per cápita, los cuáles señalan datos y cifras distantes de la realidad social, dado que generalmente no se articula la calidad y cobertura de los temas sociales, con los datos generados en los indicadores económicos mencionados. Esta desarticulación se une también a las grandes brechas entre los dueños de los factores de producción, en los sistemas capitalistas con disfraz de socialismo y humanismo, y quienes tienen la posibilidad de ofrecer en este mercado solamente su mano de obra, retribuida con salarios mínimos que no alcanzan para satisfacer las necesidades básicas, incrementando de esta manera la pobreza y el atraso generalizado.

Por su parte, David Ricardo veía el asunto del valor de los bienes como el resultado del libre juego entre la oferta y la demanda, es decir, que a un precio determinado, si la oferta del mercado es mayor que la 
demanda, se genera un excedente, lo cual requiere bajar el precio para lograr el equilibrio; al contrario, cuando a un precio determinado, si la demanda es mayor que la oferta, se genera escasez; lo cual induce a subir los precios para lograr el equilibrio de mercado, esto dado en un mercado de competencia perfecta donde no existen monopolios, oligopolios, monopsonios, oligopsonios, ni competencia monopolística.

Ricardo articuló el tema de la pobreza con la explosión demográfica en los siguientes términos: "la pobreza dependía de las dinámicas del conflicto distributivo y del crecimiento poblacional, relacionaba el problema de la pobreza con la descripción de los métodos de distribución y acumulación; con sus ideas sobre los salarios, la renta, los beneficios y el papel del Gobierno; y con el debate emprendido con Malthus acerca de la población" (Ricardo, 1986).

Se destaca en este apartado sobre la pobreza a J. S. Mill, otro de los exponentes clásicos, quien se preocupó por las medidas contra la pobreza señalando la necesidad de educar a los hijos de la clase trabajadora; no olvidó referirse a la desigualdad de los salarios de las mujeres. En el cuarto libro escrito por Mill, titulado Influencia del progreso de la sociedad sobre la producción y la distribución, se establecen alternativas para disminuir la pobreza evidenciando las que limitan la riqueza, tales como: "el aumento gradual de la producción y la población, el crecimiento perpetuado, el aumento de la seguridad de las personas y de la propiedad que propician el aumento de la producción y la acumulación, el talento comercial, el crecimiento del principio de cooperación, el progreso industrial que hace disminuir el costo de producción y las fluctuaciones de los precios" (Pelet, 2001, p. 100).

\section{La noción de riqueza}

Jenofonte estableció la importancia de la división del trabajo para generar mejores resultados en la producción de bienes, y afirmó que dicha división estaba limitada por el tamaño del mercado, una idea que se convertiría en el eje de la teoría del crecimiento con Adam Smith; sin embargo, para esa época el tema del crecimiento no fue la preocupación principal, sino la justicia, aspecto que Aristóteles equiparó 
con la igualdad, frente a la injusticia o desigualdad. Así las cosas, para Jenofonte, la compraventa para lograr ubicarse en la justicia no debe ser obligada sino voluntaria.

Otro de los exponentes del tema de la riqueza desde los griegos es Platón, quien aborda el asunto de la riqueza "tendiente a mostrar que de ninguna manera puede ser algo bueno. Se la suele considerar como algo bueno en tanto útil". Platón afirmó que existían dos tipos de riqueza: la heredada y la obtenida por sus propios medios; mencionó que el cuidado de la misma obedecía en mayor medida a la que se lograba por los propios medios y que la heredada, como no había sido producto de su propia creación, no le resultaba tan útil a su poseedor.

En el modelo de ciudad-Estado planteado por Platón, uno de los valores axiológicos más destacados fue la justicia, valor que fue considerado a partir de la ocupación de las personas, es decir, el desarrollo personal consistía en que a cada uno se le debía identificar el potencial económico, social y político que la naturaleza le había dado y a partir de ello debía asignársele su función. Condenó los excesos y la ambición de algunos a tener lo que no podían por sus limitaciones físicas o intelectuales.

Desde el punto de vista del arte de la política, Platón presenta el tema de la riqueza en relación con la virtud y la felicidad en el siguiente pasaje: "Leyes III 697 b-c. AT. Uno de los aspectos que consideró respecto a la distribución de beneficios para los seres humanos, debía obedecer a la equidad, se debían distribuir correctamente las honras y las deshonras, por tanto dio prioridad a los bienes considerados del alma antes que a los bienes materiales, en segundo lugar los bienes del cuerpo y finalmente los bienes relacionados con la fortuna" (García, 2006).

Por otra parte, Aristóteles encuentra que "la revolución (stasis) ${ }^{3}$, tiene dondequiera por causa la desigualdad [...]" (Aristóteles. La Política, 1301 b 27-28). En el libro II de La Política se afirma que "[...] es

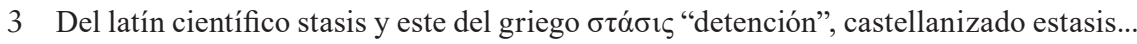
disturbios internos tanto en individuos como en la ciudad-Estado (conceptos contemporáneos similares son los de guerra civil o revolución). 
un mal que se hagan pobres muchos que fueron ricos. Gran trabajo será impedir que estos hombres sean revolucionarios" (Aristóteles. $\mathrm{La}$ Política, 1266 b 13-15). García Cataldo ilustra al respecto que "Aristóteles percibió agudamente este conflicto cuando planteó que las stasis del mundo heleno tenían su causa en la desigual distribución de la riqueza" (García, 2006, p. 6).

Los planteamientos aristotélicos respecto a la inequidad en la distribución de la riqueza como causa de las revoluciones helénicas, no distan de las causas de la revolución y el conflicto colombiano generado por las brechas económicas, sociales y políticas, evidenciadas especialmente en las cifras de pobreza e inequitativa distribución de la riqueza.

Desde el pensamiento escolástico en la categoría riqueza, señala Alberto Magno que la fortaleza y la posesión como características vinculadas al dominio, explican la idea principal de preeminencia o superposición. De este modo define cómo debe entenderse dicha fortaleza y a qué se refiere la posesión: “... en cuanto a la abundancia de bienes naturales, dice fortaleza (fortitudo), verdadera (vera), en cuanto a la misma naturaleza, e incapaz de caer (cadere non valens) en cuanto a la supresión de obstáculos; y añade que de aquello por lo que se hace señor, se habla de dominación, señor y el que domina; y es evidente cómo se diferencian entre sí" 4 .

Para esclarecer la realidad del dominio como superposición, se sirve de la definición suministrada por el propio texto del areopagita, quien afirma: "Dominación es no solo exceder a los inferiores, sino también perfecta y completa posesión de todo lo bello y lo bueno, y verdadera fortaleza incapaz de caer" ${ }^{5}$.

Finalmente, la manifestación de qué significa dominio en Alberto Magno viene enunciada en sus escritos a continuación de un problema

4 Alberto Magno, Super Dionysium De divinis nominibus, c. 12, en Opera, vol. XXXVVII/1, 429-430.

5 Pseudo-Dionisio Areopagita, De divinis nominibus, c. 12, S 2; B. R. suChla (ed.), Berlín, Walter de Gruyter, 1990, Patristische Texte und Studien, vol. 33, Corpus Dionysiacum I, 224. 
teológico y angeológico: "qué significa que Dios es Dominus... define el dominio por la superpositio, la excelencia o superposición, la cual implica una doble causa a saber: una, la abundancia de los bienes poseídos (con criterio cuantitativo y cualitativo -total, perfecta y completa-, al tiempo que es una posesión ordenada y coherente); la segunda, la integridad o fortaleza". "Esta es la definición esencial del dominio como excelencia; definición a la que recurrentemente refiere el Doctor Universal en sus distintas argumentaciones (teológicas, angeológicas, antropológicas, éticas y políticas)" (Zorroza, 2013, p. 431).

Santo Tomás por su parte, establece que la riqueza es espiritual, no le atribuye el valor material a los bienes y servicios en términos reales de mercado porque considera que la visión bienaventurada no es de este mundo, si bien es cierto la riqueza material es necesaria y deseable como instrumento para satisfacer necesidades: "Esta hermenéutica rompe el mito alusivo al mundo profano o secular que Tomás de Aquino rescata en su justa dimensión. El hombre, que gracias a la posesión de la razón es una persona y por tanto lo más perfecto de toda la creación, domina sobre los bienes de la naturaleza" (Lanas, 2007, p. 8).

La riqueza es un propósito de actualidad para los diferentes gobernantes del mundo, las políticas públicas orientadas a partir de sus propuestas de gobierno obedecen a lograr una mejor distribución de los recursos, la iluminación que brinda Tomás de Aquino a partir de los principios fundamentales de la doctrina católica, está basada en el precio justo y la distribución equitativa de la riqueza, sin desconocer que también consideró que en la medida en que cada ser humano se esforzara más, merecía más, por ello apoyó la propiedad privada como premio al trabajo.

Desde el pensamiento económico clásico uno de los primeros autores en tener acercamiento al concepto de riqueza fue Adam Smith, en su obra La riqueza de las naciones, surge como uno de los objetivos que debe alcanzar cualquier nación, pero de dónde proviene la riqueza y cuáles son las formas de alcanzarla, son interrogantes que tienen respuesta puesto que el trabajo es uno de los medios para conseguirla, gracias a esta actividad el individuo puede lograr sus bienes y generar 
procesos de acumulación, entre más productivo sea el trabajo y más división haya, la riqueza será más cercana, es decir, existe una asociación entre riqueza y división del trabajo.

Para Smith y Ricardo, la clase social de pobres estuvo ubicada siempre en la clase trabajadora que ofrecía al mercado su fuerza de trabajo, dado que adolecían de capital y de tierra; los dos autores consideraron que la ineficiencia de las instituciones del sistema capitalista no lograba la distribución de la riqueza.

Así las cosas, Ricardo y Smith señalaron que la libertad que ofrecía la mano invisible para el manejo de la oferta y la demanda en el mercado y el egoísmo individual, permitirían el beneficio global y en este modelo de libertad disminuiría la pobreza. Según Heilbroner (1992), Smith establece que las leyes del mercado, es decir el libre juego entre oferta y demanda, consienten en que la sociedad prospere o decaiga.

Para Mill, el capital es resultado de riqueza y de ahorro,

el ahorro enriquece a la comunidad al mismo tiempo que a los individuos mientras que el gasto los empobrece, lo que equivale a decir, que la sociedad en general es más rica por todo aquello que gasta en mantener y ayudar al trabajo productivo, pero más pobre por lo que consume en sus placeres, distingue entre capital fijo y capital circulante que se destruye como tal; todo aumento del capital fijo a expensas del circulante perjudica los intereses de los trabajadores (Pelet, 2001, p. 13).

John Stuart Mill explica cómo la distribución de la riqueza depende de la intervención de las decisiones de los seres humanos, a través de las instituciones, se acerca a la formulación de políticas que se asemejan a posiciones cercanas al comunismo y al socialismo, en las cuales la distribución, tanto de bienes como de servicios, debía ser más equitativa y solidaria para todos.

En la revisión de autores clásicos desde la categoría riqueza, es importante señalar que Marx ha demostrado en El capital, a través de un análisis teórico-histórico del capitalismo, que la libre competencia ha generado la concentración de la producción y que dicha concentración, 
en un cierto grado de desarrollo, conduce al monopolio; con lo cual está mostrando la dinámica propia de la formación social capitalista. Lenin en 1920, analizó en base a la concepción marxista de las formaciones sociales, las tendencias evolutivas desarrolladas por el capitalismo diferenciando dos fases en su formación: en la primera, la producción y comercialización de mercancías se realizaba a partir de relaciones de libre competencia, y en la segunda, el imperialismo, cuya esencia económica es el monopolio que se basa en la concentración de la producción y permite cada vez mayor acumulación en menos manos.

Finalmente, se considera relevante cerrar este apartado con el aporte de Arcos, quien establece que "la forma en que estén distribuidas la riqueza y las oportunidades, incide en el desarrollo de un país y en su estabilidad social y política" (Arcos, 2000); rescata de Sen que la desigualdad y la rebelión van de la mano, a pesar de su mutua relación, de lo uno no se deriva necesariamente lo otro, porque las personas no siempre expresan su inconformidad frente a la desigualdad, sin embargo, los esfuerzos que se hagan para superar el problema de inequidad generarán impacto positivo en el desarrollo, es por tanto que la lucha contra la concentración de la riqueza se convierte en su requisito.

\section{La noción de vivienda}

Se inicia la revisión de la categoría de análisis vivienda desde el pensamiento económico de los griegos, destacándose, según Bernabé, el siguiente aporte de Aristóteles: "defiende la propiedad privada para todas las clases (con excepción de los esclavos, que no son sujetos sino objetos económicos como parte de la propiedad), en razón a que la propiedad, que consideraba como natural, promovía la eficiencia económica, un planteamiento que pasó al derecho romano y que luego fundamentó las bases de los Estados nacionales emergentes a partir del siglo xv" (Bernabé, 2005, p. 89).

Desde el pensamiento económico de los escolásticos, santo Tomás manifiesta por qué la propiedad debe ser privada en los siguientes términos: "Poseer bienes es hasta necesario a la vida humana, por tres motivos: primero, porque cada uno se preocupa más asiduamente de 
procurarse aquello que es de su exclusiva propiedad, ante aquello que pertenece a todos o a más personas; ya que cada uno, por evitar la fatiga, tiende a dejar a otros cuanto corresponde al bien común como sucede allí donde hay muchos criados. Segundo, porque las cosas humanas se desarrollan con más orden, si cada uno tiene la tarea de proveer algo a través del propio esfuerzo; mientras que sería un desorden si todos, indistintamente proveyeran a cada cosa. Tercero, porque así está más garantizada la paz entre los hombres, concentrándose cada uno en sus cosas. En efecto, vemos que entre los que poseen algo en común, a menudo surgen disputas" (S.Th: II-II-66, 2 in corpore). (Lara, s. f., p. 11).

La división de la propiedad, no fue introducida originalmente por la naturaleza, sino que fue añadida por la razón para beneficio de la sociedad humana. "Esta explicación no contradice el principio de las demostraciones de la ley canónica, y puede, incluso, haber estado influida por ella, pero se trata de una solución mucho más elegante que evita, además, una evidente ambigüedad, constituye indudablemente una gran contribución a la teoría de la propiedad" (Parasi, 2007, p. 36)

Es evidente que para lograr vivienda propia se requiere trabajar durante mucho tiempo o heredarla, pero indistintamente de cómo se adquiere, se considera una forma de acumulación de riqueza. El trabajo como factor de producción se incorpora al mercado y permite acceder a bienes y servicios para satisfacer las necesidades de los individuos, entre otros la vivienda, adquirida a través de un derecho de propiedad que se establece en un título, a partir de un negocio de confianza entre dos actores, en un sistema económico capitalista. Sin embargo, la economía mundial ha justificado crisis especialmente en términos financieros, por la falta de confianza entre los mencionados actores sociales, causa planteada desde Smith, así: "El comercio y las manufacturas pocas veces pueden florecer mucho tiempo, en cualquier Estado que no disfruta de una administración regular de la justicia, en los que las personas no se sienten seguras en la posesión de sus bienes, en los que la fe de los contratos no es compatible con la ley" (Smith, 1776a, p. 1227). 
En la crisis financiera de EE. UU. en el año 2008, se evidenció la pérdida de confianza y el negocio que vislumbraron como exitoso fue el de los préstamos para vivienda, dado que estaría respaldado el capital, a partir de las hipotecas y estas permitirían recuperar la confianza y sobre todo las utilidades en el negocio financiero a partir de las tasas; nuevamente la mano invisible de Adam Smith se ve reflejada en la confianza del mercado financiero orientado a la vivienda, fue precisamente esa confianza la que les permitió otorgar hipotecas subpri$m e$, que se otorgaban por valores superiores a los del bien a adquirir y con riesgo de no pago, lo que generó una amenaza más grave en términos económicos, dado que cuando las tasas de interés empezaron a subir, la demanda de casas disminuyó y las hipotecas subprime ya no respaldaban los títulos otorgados, es decir, por falta de confianza no funcionó la mano invisible en el mercado de la vivienda.

El reformador francés Francisco Place, autor de la obra Ilustración $y$ pruebas del principio de población (1822) y Robert Dale Owen, autor de Fisiología moral (1831), realizaron estudios para establecer una relación entre población, desarrollo y crecimiento demográfico, e identificaron cuatro fases en las sociedades: antiguo régimen democrático, comienzo de la transición, fin de la transición y régimen demográfico moderno. Ron Lestaeghe y Van de Kaa (1986), identifican una fase con el concepto o teoría de la segunda transición demográfica, para referirse a la constitución y reproducción de las familias después de la Segunda Guerra Mundial.

Esta teoría entra en contradicción con los postulados de Malthus, que durante la Revolución Industrial, predijo que "el crecimiento de la población responde a una progresión geométrica, mientras el aumento de los recursos para su supervivencia lo hace en progresión aritmética, lo que llevaría a la pauperización gradual de la especie humana e incluso podría provocar su extinción, lo que se ha denominado catástrofe maltusiana" (Malthus, 1798).

Cualquier observador sin prejuicios se da cuenta enseguida de que en la medida que se centralizan los medios de producción, se hacinan también las masas de obreros en el mismo espacio; y que, por tanto, 
cuanto más rápidamente avanza la acumulación capitalista, más míseras son las viviendas obreras. A simple vista se observa cómo el "embellecimiento" de las ciudades, consiguiente a los progresos de la riqueza mediante la demolición de los barrios mal construidos, la construcción de palacios para bancos, grandes almacenes, etc., el ensanchamiento de las calles para el tráfico comercial y los coches de lujo, el tendido de tranvías, etc., va arrinconando a los obreros en tugurios cada vez peores y más hacinados (Marx, 2008).

Dados los anteriores planteamientos, se puede evidenciar que el proceso de urbanización y de creación de ciudades, surge como respuesta a los procesos de industrialización, que requerían mano de obra disponible y dotación de vivienda, esta necesidad fue ampliando la escasez de espacio y el incremento de precios de las mismas, problema que a través de la historia no ha sido resuelto.

\section{Interpretación contemporánea de las categorías: pobreza, riqueza y vivienda en Colombia}

Desde la economía social, tal como se evidenció en la apertura de este capítulo, el desarrollo económico y social se debe articular para construir una sociedad más justa, solidaria, incluyente, con mayores y mejores posibilidades de satisfacción de necesidades básicas humanas, para cimentar la justicia distributiva en términos de riqueza, generar menores índices de pobreza, orientar la sostenibilidad y sustentabilidad en el tema ambiental y procurar menos corrupción en las instituciones. Su pretensión debe obedecer a una amplia cobertura tanto en área como en población, de infraestructura de apoyo a la producción y reproducción social de la población como la vivienda, lo cual indudablemente generaría una respuesta de paz en las regiones rurales y urbanas del país.

Así las cosas, la experiencia institucional colombiana en materia de política pública social orientada para satisfacer una necesidad como la vivienda de interés social, data de 1932, año en que se fundó el Banco Central Hipotecario con el objetivo principal de promover el sector de la construcción a través del crédito hipotecario; en 1939 se creó el 
Instituto de Crédito Territorial (ICT), entidad que, hasta 1991, fue la encargada de construir y otorgar crédito a la compra de vivienda para las clases menos favorecidas. Mediante este sistema el Gobierno subsidiaba las tasas de interés de los créditos y el precio de las viviendas las cuales construía directamente o por contrato con urbanizadores privados. "El ICT se financiaba fundamentalmente con recursos del presupuesto nacional, con inversiones forzosas del sistema financiero, con la recuperación de su cartera y en ocasiones recibió créditos externos en condiciones blandas" (Chiape, 1999).

Ante la extensión de la pobreza en todo el país, Currie en 1949, en su informe de desarrollo económico para Colombia, estableció como solución al tema del desarrollo atraer a los trabajadores rurales subempleados a ciudades dinámicas y no a lugares con mucho menos futuro, justificación basada en que una demanda latente de vivienda se actualizaría mediante un estímulo a los ahorros para la construcción de vivienda, un proceso que permitiría obtener mayores ingresos reales. "Estas ganancias, respaldadas por producción real, luego se gastan en (o se intercambian recíprocamente por) el producto de otros sectores. Estos gastos generan naturalmente lo que se puede llamar economías pecuniarias externas laterales para otros sectores que ahora pueden vender más alimentos, vestuario, muebles, etc., así como más inversiones en vivienda, financiadas con el aumento de los ahorros provenientes de los mayores beneficios y salarios obtenidos en la producción para la cual existe y se puede actualizar la demanda final latente" (Sandilands, 2015).

Cabe mencionar en este apartado la importancia de diferentes estudios contratados por el Gobierno colombiano, en el período 1953-1957, tales como, dice García (2013):

Lebret, CEPAL, FAO, Lillienthal, Electricité de France y Gibbs and Hill de Estados Unidos, diagnosticaron la problemática social, económica y de infraestructura productiva del país destacando la falta de: vías, distritos de riego, electrificación, comunicaciones, dotación de servicios públicos y una distribución más equitativa de la tierra, tanto en las zonas rurales como urbanas; igualmente señalaron la debilidad en la cobertura y calidad de los servicios sociales de salud, 
educación y vivienda, problemática que requería entonces de mayor compromiso del Gobierno en la formulación de una política pública que orientara programas y proyectos que apuntaran a una mejor calidad de vida para los colombianos” (García, 2013, p. 167).

En 1972 el presidente Misael Pastrana Borrero buscó una nueva directriz de desarrollo económico basada, entre otras estrategias, en el fortalecimiento del sector de la construcción de vivienda. Durante este Gobierno se crearon dos herramientas que transformarían la política de vivienda: las Corporaciones de Ahorro y Vivienda (CAV) y la Unidad de Poder Adquisitivo Constante (UPAC).

Hacia finales de los años ochenta, en un proceso de reflexión sobre la vivienda de interés social ${ }^{6}$, se planteaban soluciones al problema

6 Artículo $91^{\circ}$.- Concepto de vivienda de interés social. El artículo 44 de la Ley $9^{\text {a }}$ de 1989, quedará así: "Se entiende por viviendas de interés social aquellas que se desarrollen para garantizar el derecho a la vivienda de los hogares de menores ingresos. En cada Plan Nacional de Desarrollo el Gobierno Nacional establecerá el tipo y precio máximo de las soluciones destinadas a estos hogares teniendo en cuenta, entre otros aspectos, las características del déficit habitacional, las posibilidades de acceso al crédito de los hogares, las condiciones de la oferta, el monto de recursos de crédito disponibles por parte del sector financiero y la suma de fondos del Estado destinados a los programas de vivienda. En todo caso, los recursos en dinero o en especie que destine el Gobierno Nacional, en desarrollo de obligaciones legales, para promover la vivienda de interés social se dirigirá prioritariamente a atender la población más pobre del país, de acuerdo con los indicadores de necesidades básicas, insatisfechas y los resultados de los estudios de ingresos y gastos".

Artículo $83^{\circ}$.- Definición de vivienda de interés social. Reglamentado por el Decreto Nacional 4466 de 2007. De conformidad con el artículo 91 de la Ley 388 de 1997, la vivienda de interés social debe reunir elementos que aseguren su habitabilidad, estándares de calidad en diseño urbanístico, arquitectónico y de construcción. El valor máximo de una vivienda de interés social será de ciento treinta y cinco salarios mínimos legales mensuales vigentes $(135 \mathrm{smlm})$.

A su vez, el Decreto 2190 de 2009 reglamentario de la Ley $3^{\text {a }}$ de 1991,señala que la Vivienda de Interés Social (VIS), es aquella que reúne los elementos que aseguran su habitabilidad, estándares de calidad en diseño urbanístico, arquitectónico y de construcción cuyo valor máximo es de ciento treinta y cinco salarios mínimos legales mensuales vigentes $(135 \mathrm{smlm})$ y como Vivienda de Interés Social Prioritaria (VIP), aquella vivienda de interés social cuyo valor máximo es de setenta salarios mínimos legales mensuales vigentes $(70 \mathrm{smlm})$. 
de tierras y se cuestionaba el esquema financiero del ICT, al tiempo que se expresaba preocupación por la eficiencia administrativa de la entidad, esta discusión derivó en la Ley $3^{a}$ de 1991, con la cual se reorientó la política, de acuerdo con las tendencias internacionales, hacia un esquema de subsidios ${ }^{7}$ basado en mecanismos de mercado. En esta forma, el Estado abandonó su papel de intermediario financiero y constructor de vivienda y se sustituyó el ICT por el Instituto Nacional de Vivienda de Interés Social y Reforma Urbana (Inurbe), entidad encargada de administrar el sistema de subsidios y prestar asistencia técnica.

El desarrollo de la política de vivienda de interés social a partir de 1991, cuando se adoptó el sistema de subsidios a la demanda para sustituir el antiguo esquema en que el Estado era directamente constructor de vivienda, proveedor de crédito y de subsidios, persigue incrementar la demanda efectiva de vivienda de interés social mediante el otorgamiento de subsidios a los beneficiarios, los que complementados con crédito y con un porcentaje de ahorro familiar, deberían permitir incluso a los más pobres acceder al mercado de vivienda, inclusive para la población desplazada ${ }^{8}$.

7 La Ley $3^{\mathrm{a}}$ de 1991 en su artículo $6^{\circ}$ define el subsidio familiar de vivienda: Artículo $6^{\circ}$.- Establécese el Subsidio Familiar de Vivienda como un aporte estatal en dinero o en especie, otorgado por una sola vez al beneficiario con el objeto de facilitarle una solución de vivienda de interés social, sin cargo de restitución siempre que el beneficiario cumpla con las condiciones que establece esta Ley. La cuantía del subsidio será determinada por el Gobierno Nacional de acuerdo con los recursos disponibles, el valor final de la solución de vivienda y las condiciones socioeconómicas de los beneficiarios.

8 El Decreto 951 de 2001 en su artículo $1^{\circ}$ lo definió así: Artículo $1^{\circ}$.- Del subsidio familiar de vivienda para población desplazada. Tal como lo establece el artículo $6^{\circ}$ de la Ley $3^{\text {a }}$ de 1991, el Subsidio Familiar de Vivienda es un aporte estatal en dinero o especie, otorgado por una sola vez al beneficiario con el objeto de facilitarle una solución de vivienda de interés social, sin cargo de restitución, siempre que el beneficiario cumpla con las condiciones que se establecen en la Ley $3^{\mathrm{a}}$ de 1991 y aquellas que la modifiquen o adicionen.

Artículo $11^{\circ}$.- Subsidio al arrendamiento. Para el caso de población desplazada, el subsidio familiar de vivienda podrá otorgarse para el pago del arrendamiento de un inmueble, dentro de las condiciones establecidas por este Decreto 951 de 2001, en cuyo caso este se pagará durante un plazo máximo de 24 meses. 
Respecto al perfil de la demanda global, las políticas fiscales encargadas de generar la redistribución del ingreso no son completas y muchas veces generan ventajas para las multinacionales, o en el peor de los casos, ellas deciden salir de los países de grandes tasas de tributación y migrar a aquellos en los que estos son muy bajos e incluso nulos, lo que los convierte en un sinsentido al momento de pensar el sistema industrial como factor de crecimiento con irradiación social.

Este desplome de los Estados nacionales y el apalancamiento de las multinacionales en este nuevo orden mundial, y en el nuevo capitalismo, según Furtado “... está generando grandes cambios estructurales que se traducen en la creciente concentración del ingreso y en formas de exclusión social manifiesta en todos los países" (Furtado, 1988).

Por su parte, Raúl Prebisch señaló que la distribución inequitativa de los frutos del desarrollo se debía principalmente a "la apropiación por los estratos superiores de la estructura social de una parte considerable del fruto del progreso técnico en forma de excedente económico... el sistema tiende así a excluir grandes masas que quedan vegetando en el fondo de la estructura social" (Prebisch, 1981, p. 15). La exclusión de la que habló Prebisch tenía un contenido económico, la necesidad de un uso social del excedente implicaba para él la imposibilidad de participar en los beneficios de la acumulación de capital para una importante parte de la población, y esto por la doble vía la imposibilidad de consumo y de participación en la producción, es decir, mayor pobreza y desempleo.

Se requieren grandes esfuerzos para superar los problemas institucionales, fiscales y financieros desde los gobiernos de turno, es por eso que cabe mencionar algunos desafíos planteados en los últimos planes de desarrollo de Colombia “... a) aumentar la eficiencia del gasto social para que los mayores recursos se traduzcan en mejores resultados; b) mejorar la focalización del gasto para que los recursos lleguen a los más necesitados; c) consolidar un sistema de protección social para que las crisis económicas no comprometan, por completo, las posibilidades futuras de los grupos más vulnerables” (Ley 182 de 2003). 
Durante las cuatro últimas décadas, Colombia ha progresado de modo continuo y significativo en el campo social. Han mejorado las condiciones de vida de sus habitantes y se ha ampliado el acceso de la población a los servicios básicos de educación, salud y vivienda. Se ha incrementado el ingreso per cápita y ha disminuido pausadamente la aún elevada proporción de personas bajo la línea de pobreza (LP).

¿Por qué abordar el tema de la distribución de la riqueza como un problema central de investigación en la ciencia económica y en particular de la economía social? Abordar temas como la desigualdad y el empleo es pertinente, así como el problema de la distribución de la riqueza y de las rentas del capital. También lo es buscar respuestas a si la dinámica de la acumulación del capital privado conduce inevitablemente a la acumulación de riqueza en cada vez menos manos. Según Amartya Sen, las características de la desigualdad en distintos espacios como ingresos, riquezas, felicidad, etc., tienden a distanciarse una de otra dada la heterogeneidad de la gente. Unos ingresos idénticos pueden ir acompañados de diferencias significativas de riqueza. La misma cantidad de riqueza puede coexistir con diferentes niveles de felicidad, dado que la diversidad humana está relacionada con conflictos sustantivos económicos y sociales de contextos diferentes desde lo económico, social, institucional, fiscal, financiero y humano; es por ello que en sus análisis e interpretaciones se deben reconocer esos contextos, en aras de una mejor distribución de la riqueza para contribuir a la pacificación colombiana. Indudablemente, estas inquietudes han sido una preocupación de los más importantes autores del pensamiento económico griego, escolástico, clásico y contemporáneo como lo muestra este capítulo.

\section{Conclusiones}

- El interés de reconstruir, a partir de una explícita opción metodológica, la historia del pensamiento económico con un procedimiento retrospectivo, es resaltar los antecedentes teóricos y conceptuales de eminentes autores desde aquellos griegos, 
escolásticos y clásicos, propios de una obra científica, para demostrar su vigencia en la construcción de doctrinas, teorías, modelos económicos y políticas públicas, planteados por autores más recientes en aras de lograr la inclusión, la equidad y la solidaridad para la humanidad.

- Como una alternativa de equidad, Jenofonte (Oec. xx. 15) mencionó respecto a la situación difícil de desempleo de los pobres y campesinos, que este escenario los obligaría a convertirse en delincuentes, por tanto no tendrían alternativa alguna y se ganarían el sustento robando o mendigando, drama que aún se observa en algunas regiones colombianas que por la falta de apoyo institucional desde la política pública, no responde a la generación de empleo; por tal razón concibe pobreza y atraso generalizado, que en muchas ocasiones no solo forja delincuencia sino un conflicto inacabado.

- Se puede afirmar que la política para Aristóteles, no se reduce a una técnica del interés y la defensa del poder, en un sentido más amplio el estagirita aspira a que dicha disciplina fortalezca el bienestar y la excelencia de los ciudadanos: "hacer buenos a los hombres" (Livov, 2004, p. 242). La política, por lo tanto, no puede perdurar indiferente ante el difícil problema de la pobreza y no deja de instaurar medidas para evitar el empobrecimiento de los ciudadanos.

- Es indiscutible que los aportes de santo Tomás, sobre la pobreza, riqueza y propiedad privada, conservan la vigencia para el servicio del ser humano en muchas variables económicas actuales, por ejemplo: los índices macroeconómicos, la inflación, la tecnología, la redistribución de la riqueza, la competitividad y la globalización entre otras, todas ellas variables de ayer y hoy que están al servicio del ser humano, de la persona, para aspirar al bien común del pensamiento económico de Tomás de Aquino.

- Según Smith, la pobreza surge con la propiedad privada y las normas, las leyes o la regulación como se establece en los 
tiempos modernos; quienes solo cuentan con sus manos para producir su sustento y el de su familia, anhelan merecer aunque sea una parte de la riqueza de otros. Dada la oposición de Smith a la intervención del Estado (establece que este es el culpable de la pobreza), señala que en el sistema económico primitivo solo se necesitaba de las leyes de la naturaleza y por tanto todo lo que existía en términos de bienes era de todos.

- Platón consideró importante la disminución de las desigualdades para llegar a un estado ideal de los ciudadanos, señaló que dada la necesidad de abastecer de bienes y servicios a la comunidad, surgió el Estado como respuesta a un modelo de ciudad-Estado que pudiera orientar la satisfacción de vivienda, alimentación, vestido y salud como necesidades básicas para la reproducción social de la población.

- Aristóteles manifestó que la riqueza no tenía límites, esta visión forma parte de la naturaleza de la ciencia económica, en la que se asume que los recursos o factores de producción, son escasos pero las necesidades son ilimitadas. Sin embargo, el filósofo estableció una diferencia entre riqueza y acumulación de bienes así: no es lo mismo tener muchos bienes, que disfrutarlos; usó el ejemplo del rey Midas que, según dice la leyenda, todo lo que tocaba lo convertía en oro, pero no podía disfrutar de nada, ya que a pesar de tener cuantiosos bienes le resultaba improbable deleitarse con ellos. Esta reflexión permite probar que la riqueza no se establece a partir de los bienes que se posean, sino de la disposición que se pueda tener de ellos.

- Marx plantea una crítica a Ricardo y a Smith, en el sentido de que la fuerza de trabajo permite obtener riqueza de los capitalistas a través de la plusvalía, es decir, un incremento del valor a través del trabajador quien produce valor y aumenta la riqueza, la cual no se distribuye al trabajador generando inequidad en la distribución de la riqueza, lo que genera pobreza ya que el beneficio es para los capitalistas. 
- La vivienda se constituye en una forma de ahorro y por ende de acumulación de capital. Sin embargo, la vivienda no es en sí misma un factor productivo, sino un factor necesario en el proceso de conformación de la sociedad industrial. Uno de los elementos en la transformación del feudalismo al capitalismo, es la creación de centros urbanos, dotados de servicios públicos, que permiten tener cerca la mano de obra para ser utilizada en las fábricas.

- $\quad$ Es el trabajador quien debe suministrarse su vivienda, ya que el capitalista paga un salario para que aquel se provea alimento, salud, educación y vivienda para él y su familia. El patrono no se hace responsable de proveer esos servicios. Las ciudades se convierten entonces, en lugares fundamentales para permitir el desarrollo industrial y el crecimiento económico, la industrialización exige la urbanización.

- La relectura de los postulados de economía y humanismo de Louis Joseph Lebret orientados en la misión que lideró en Colombia con la pretensión de diagnosticar y formular propuestas de intervención pacificadora para el país, y el acumulado de experiencias hasta el presente pueden inspirar un renovado modo de pensar y actuar, especialmente a profesionales y estudiosos de diversas disciplinas, en pro de un desarrollo integral, humano y sustentable, atentos al "cuidado de la casa común” al que exhorta hoy el papa Francisco, para disminuir las desigualdades especialmente en la distribución de la riqueza.

\section{Referencias}

Álvarez, J. (2009). Aristóteles: perì demokratías. La cuestión de la democracia. Isegoría, (41), 69-101.

Arcos, O. et al. (2000). Inserción precaria, desigualdad y elección social. Bogotá D. C., Colombia: Ediciones Antropos Ltda. CINEP.

Bernabé, A. (2005). Aristóteles; Constitución de los atenienses, Madrid, España: Abada Editores.

Calvo, T. (2001). Aristóteles y el aristotelismo. Madrid, España: Akal. 
Campelo, A. (1998). Cidadania e revolução na Política de Aristóteles. Lisboa, Portugal: Vega.

Chaves, J. (2004). Desarrollo tecnológico en la primera revolución industrial. Norba. Revista de historia, (17), 93-109.

Chiape, M. (1999). Proyecto Interdivisional CEPAL "Instituciones y mercados”, financiado por GTZ, Santiago de Chile.

Congreso de la República de Colombia. (2003). Ley 812 de junio 26, Por la cual se aprueba el Plan Nacional de Desarrollo 2003-2006 hacia un estado comunitario.

Gache, F., y Otero, D. (2010). Adam Smith: la mano invisible o la confianza. Revista Visión de Futuro, Año 7 N² 2, Volumen 14, México D. F., México: UNAM.

Fresneda, O., González, J., Cárdenas, M., y Sarmiento, L. (2009). Reducción de la pobreza en Colombia: el impacto de las políticas públicas. Capítulo V. Bogotá D. C., Colombia: PNUD.

García, O. (2013). Colonización del Carare, Santander, Colombia, 1953-1957. Tesis doctoral en Historia, p. 156. UPTC, Tunja, Boyacá, Colombia.

García, H. (2006). La Constitución de Atenas de Aristóteles: visión retrospectiva de la historia y la institucionalidad helenas. Tesis para optar al grado académico de magíster en Historia con mención en Historia Europea, Santiago de Chile.

García, H. (2011). Algunos aspectos de la ciencia política aristotélica en la Ética Nicomaquea. REC 38: 99-120.

Gómez, A. (2011). Aristóteles; Política. México D. F., México: UNAM.

Guntiñas Tuñón, O. (1984). Jenofonte, Obras menores. Madrid, España: BCG. Kropotkin, P. (1995). Kropotkin. The conquest of bread and Others Writings. (Cambridge Texts in the History of Political Thought), London, UK: Edited by Marshall S. Shatz.

Lanas, S. (2007). De la traducción de Odd Langholm. La economía en Tomás de Aquino. Revista Observaciones Filosóficas. Universidad Andrés Bello, Valparaíso, Chile.

Livov, G. (2004). Espacio de convergencia entre memoria y ley en la filosofía práctica aristotélica. En Santa Cruz, M., Marcos, G., y Di Camillo, S. (comps.) Diálogo con los griegos. Estudios sobre Platón, Aristóteles y Plotino, Buenos Aires, Argentina: Ediciones Colihue, 239-257. 
Maceri, S. (2009). El concepto de riqueza en Platón en tanto impedimento para el Estado justo. Energeia, 5(1), pp. 165-184.

Marx, C. (2008). El carácter antagónico de la acumulación capitalista. Recuperado de: http://aristobulo.psuv.org.ve/wp-content/uploads/2008/10/ marx-karl-el-capital-tomo-i1.pdf

Marx, C. (2016). El materialismo histórico. Recuperado de: http://mgar.net/ docs/marx.htm

Márquez, Y., y Silva, J. (2008). Pensamiento Económico con énfasis en pensamiento económico público. Bogotá D. C., Colombia: ESAP.

Méndez. V. (2012). El problema de la pobreza en la utopía aristotélica. Coloquio Internacional. México D. F., México.

Minsky H. (1992). The Financial Instability Hypothesis. Working paper $\mathrm{N}^{\circ}$ 74, prepared for Handbook of Radical Political Economy, edited by Philip Arestis and Malcolm Sawyer, Edward Elgar Aldershot. New York.

Morrow, G. L. (1966). Adam Smith: Moralist and Philosopher. En J. M. Clark, P. H. Douglas, J. H. Hollander, G. L. Morrow, M. Palyi y J. Viner. Adam Smith, 1776-1926. Lectures to commemorate the sesquicentennial of the publication of the Wealth of Nations, New York, August M. Kelley.

Nieto, E. (2010). La figura del pobre y el debate sobre la pobreza en Grecia. Memoria para optar al grado de Doctor, Universidad Complutense de Madrid. Madrid, España.

Parasi. D. (2007). De la traducción de Odd Langholm. La Economía en Tomás de Aquino. Revista Observaciones Filosóficas. Universidad Andrés Bello, Valparaíso, Chile.

Pelet. C. (2001). John Stuart Mill, la etapa de madurez de la escuela clásica. Revista Acciones e investigaciones sociales. Universidad de Zaragoza, España.

Prebisch, R. (1981). Capitalismo periférico: crisis y transformación. México D. F., México: Fondo de Cultura Económica.

Ramírez, A. (2002). Aristóteles; Retórica. México D. F., México: UNAM.

Rico Gómez, M. (1989). La república de los lacedemonios. La república de los atenienses. Madrid, España: CEC. 
Ricardo, D. (1986). On the Principles of Political Economy and Taxation. Editado por Piero Sraffa, Cambridge, UK: Cambridge University Press. Ricardo, D. (1817): Principios de economía política y tributación. México D. F., México: Fondo de Cultura Económica.

Sancho, L. (2011). Riqueza, impiedad y üßpıs (bybris) en el Contra Midias de Demóstenes. Emerita, 79(1), 31-54.

Schumpeter, J. (1966). History of Economic Analysis, 6 a ed., editado por Elizabeth Boody Schumpeter, Oxford, UK: Oxford University Press.

Smith, A. (1776). An Inquiry into the Nature and Causes of the Wealth of $\mathrm{Na}$ tions. Editado por R. H. Campbell, A. S. Skinner y W. B. Todd, Oxford, UK: Oxford University Press, 1981.

Smith, A. (1982). Lectures on jurisprudence. Edited by R. L. Meek, D. D. Raphael and P. G. Stein. Indianapolis, IN: Liberty Fund.

Smith, A. (1987). Lectures on Jurisprudence, en R. L. Heilbroner. The Essential Adam Smith. New York, W. W. Norton \& Company.

Smith, A. (1987). The History of Astronomy, en R. L. Heilbroner, The Essential Adam Smith. New York, W. W. Norton \& Company.

Smith, A. (1987). The Theory of Moral Sentiments, en R. L. Heilbroner. The Essential Adam Smith. New York, W. W. Norton \& Company.

Sandilands, R. (2015). La misión del Banco Mundial a Colombia de 1949 y las visiones opuestas de Lauchlin Currie y Albert Hirschman. Revista de Economía Institucional 17, 32, 2015, pp. 213-232. Bogotá D. C., Colombia.

Soto, L. (2011). Fragmentos de una utopía real: Aristóteles y la democracia ateniense. En Sierra González, A., y Romero Morales, Y. (eds.). Actas del V Congreso Internacional de la Sociedad Española de Filosofía "Razón, crisis y utopía”, Santa Cruz de Tenerife, España: 311-322.

Sraffa, P. (1973). The Works and correspondence of David Ricardo. Vol. VII. Letters 1816-1818, Cambridge, UK: Cambridge University Press.

Zorroza, M. I. (2013). La definición del dominio según Alberto Magno. Cauriensia: revista anual de Ciencias Eclesiásticas, (8), 411-432. 
